\title{
Presence and severity of lower urinary tract symptoms are inversely correlated with the risk of prostate cancer on prostate biopsy
}

\author{
Antonio CICIONE 1 *, Luigi CORMIO ${ }^{2}$, Francesco CANTIELLO ${ }^{1}$, \\ Italo M. PALUMBO 1, Cosimo DE NUNZIO ${ }^{3}$, Estevao LIMA ${ }^{4}$, \\ Giuseppe UCCIERO ${ }^{1}$, Giuseppe CARRIERI ${ }^{2}$, Rocco DAMIANO ${ }^{1}$
}

\begin{abstract}
1Unit of Urology, Magna Graecia University of Catanzaro, Catanzaro, Italy; ${ }^{2}$ Department of Urology and Renal Transplantation, University of Foggia, Foggia, Italy; ${ }^{3}$ Department of Urology, Sant'Andrea Hospital, Sapienza University of Rome, Rome, Italy; ${ }^{4}$ Life and Health Sciences Research Institute, University of Minho, Braga, Portugal *Corresponding author: Antonio Cicione, Magna Graecia University, 88100 Viale Europa, Catanzaro, Italy. E-mail: acicione@libero.it
\end{abstract}

\section{A B S T R A C T}

BACKGROUND: The assessment of lower urinary tract symptoms (LUTS) is common part of urological investigation. Furthermore, patients bother of prostate cancer (PCa) when they are affected of LUTS. This study was aimed to determine whether the presence and severity of LUTS, as assessed by the International Prostate Symptoms Score (IPSS), could help to identify patients at higher risk of prostate cancer (PCa) on prostate biopsy (PBx). In this effort, an initial PCa predictive model was calculated and IPSS was subsequently added. The diagnostic accuracy of both models was compared. METHODS: The analysis of prospectively collected data of patients scheduled for PBx at four academic hospitals between January 2012 and June 2015 was performed. Univariate and multivariate analysis assessed the correlation between the IPSS and the risk of being diagnosed with $\mathrm{PCa}$; Receiver operator characteristic curve (ROC) analysis evaluated the predictive models including or not the IPSS.

RESULTS: Of the 1366 enrolled patients, 706 (52\%) were diagnosed with PCa. Patients with PCa had a significantly lower IPSS (10.6 \pm 7.4 vs. 12.7 \pm 8.1$)$ than those with benign diagnosis. Multivariate logistic regression analysis showed that age, prostate-specific antigen (PSA), prostate volume and IPSS were the most significant predictors of PBx outcome, (OR 1.61, $\mathrm{P}=0.001 ; \mathrm{OR} 1.20, \mathrm{P}=0.001$; OR 0.97, $\mathrm{P}=0.001$; OR $0.74, \mathrm{P}=0.004$; respectively). ROC curve analysis showed that the addition of IPSS to the predictive model based on age, PSA, DRE and prostate volume significantly improved the model diagnostic accuracy (AUC: 0.776 vs. $0.652 ; \mathrm{P}=0.001$ ).

CONCLUSIONS: Presence and severity of LUTS are inversely correlated with the risk of being diagnosed with PCa at PBx. Incorporating the IPSS into predictive models may reduce the risk of unnecessary PBxs.

(Cite this article as: Cicione A, Cormio L, Cantiello F, Palumbo IM, De Nunzio C, Lima E, et al. Presence and severity of lower urinary tract symptoms are inversely correlated with the risk of prostate cancer on prostate biopsy. Minerva Urol Nefrol 2017;69:486-92. DOI: 10.23736/S0393-2249.17.02737-0)

Key words: Lower urinary tract symptoms - Biopsy - Prostatic neoplasms.

$\mathrm{P}_{\mathrm{s}}$ rostate biopsy $(\mathrm{PBx})$ is the standard method for diagnosing prostate cancer $(\mathrm{PCa})$ however the diagnostic yield of this procedure remains low. As a matter of fact, in current clinical practice the diagnostic yield of a first extended PBx prompted by an elevated serum prostate-specific antigen (PSA) level and/or an abnormal digital rectal examination (DRE) is in the range of $40 \% .{ }^{1}$ Such cancer detection rate (CDR) drops to approximately $25 \%$ in the setting of screening programs, i.e. patients with serum PSA between 2.5 and $10 \mathrm{ng} / \mathrm{mL} .{ }^{2}$

Predictive models that combine PSA and DRE with age and prostate volume, other two readily available clinical parameters that correlate with the risk of being diagnosed with 
PCa, have been shown to provide better predictive accuracy than PSA and DRE. ${ }^{3}$ Therefore, the identification of further non-invasive and readily available clinical predictors that would increase the predictive accuracy of such models would be extremely welcome.

In clinical practice, candidates to PBx have been seeking urological consultation because of an elevated serum PSA or, more often, because of lower urinary tract symptoms (LUTS) leading to the clinical findings of an elevated serum PSA and/or an abnormal DRE. This observation has opened a debate regarding the correlation between LUTS and the risk of being diagnosed with $\mathrm{PCa}$. To date, some studies have shown a positive while others a negative correlation between the two conditions (Table I);4-11 such discrepancy is probably due to the fact that most studies suffer biases such as heterogeneous patients' population, lack of validated questionnaires, and retrospective nature.

The present multicenter study therefore aimed to determine whether: 1) the presence and severity of LUTS, assessed by the International Prostate Symptom Score (IPSS), predict the risk of being diagnosed with PCa on PBx; 2) the addition of the IPSS improves the diagnostic accuracy of the predictive model based on age, PSA, DRE and prostate volume.

\section{Materials and methods}

Data of patients scheduled for ultrasoundguided transrectal PBx at four urological tertiary academic hospitals because of increased serum PSA ( $\geq 4 \mathrm{ng} / \mathrm{mL}$ ) and/or abnormal DRE were prospectively entered into the institutional review board approved database of each institution. All patients filled in the IPSS questionnaire and underwent PSA measurement before transrectal ultrasonography (TRUS), which was used to determine prostate volume by means of the ellipse formula and to guide transrectal prostate sampling. Following periprostatic nerve block or topical anesthetic creams, ${ }^{12}$ all patients received an extended PBx including 12 to 18 cores.

TABLE I.- The main studies on prostate cancer and urinary symptoms correlation, an overview.

\begin{tabular}{|c|c|c|c|}
\hline Author and publication year & Study setting & Sample size patients & Mean finding and study features \\
\hline Catalona et al. $1994{ }^{4}$ & PCa screening study & 6630 & Absence of LUTS is predictive of $\mathrm{PCa}$ \\
\hline Porter et al. $2004^{5}$ & Prospective study & 411 & $\begin{array}{l}\text { AUASS less than } 7 \text { is predictive of a } \\
\text { positive biopsy - A sextant biopsy } \\
\text { sampling was also used }\end{array}$ \\
\hline \multirow[t]{2}{*}{ Collin et al. $2008^{6}$} & $\begin{array}{c}\text { PCa treatments comparison } \\
\text { PROTECT Study }\end{array}$ & 65871 & $\begin{array}{l}\text { LUTS among men with a PSA level of } \geq 3 \\
\text { ng/mL were negatively associated with } \\
\text { prostate cancer }\end{array}$ \\
\hline & & & $\begin{array}{l}\text { Random cohort sapling, ICS male } \\
\text { questionnaire }\end{array}$ \\
\hline Frånlund et al. 20127 & $\begin{array}{l}\text { PCa screening study } \\
\text { Gothenburg study }\end{array}$ & 2353 & $\begin{array}{l}\text { Presence of voiding symptoms were all } \\
\text { inversely associated with the risk of } \\
\text { detecting prostate cancer in a screening } \\
\text { setting. A self-administrated questionnaire } \\
\text { was used }\end{array}$ \\
\hline Ito et al. $2013^{8}$ & $\begin{array}{l}\text { Retrospective biopsy } \\
\text { cohort analysis }\end{array}$ & 1467 & $\begin{array}{l}\text { Absent or mild lower urinary tract } \\
\text { symptoms are positively associated with } \\
\text { prostate cancer and high-grade disease } \\
\text { regardless of the prostate volume }\end{array}$ \\
\hline Oh et al. 20139 & $\begin{array}{l}\text { Retrospective biopsy } \\
\text { cohort analyses }\end{array}$ & 3107 & $\begin{array}{l}\text { PCa was detected less commonly among } \\
\text { men with higher LUTS scored by IPSS }\end{array}$ \\
\hline Matsubara et al., $2006{ }^{10}$ & PCa screening & $\begin{array}{c}3511 \\
178 \text { underwent biopsy }\end{array}$ & $\begin{array}{l}\text { No significant difference was noted in the } \\
\text { IPSS scores between men with cancer and } \\
\text { the others sextant sampling }\end{array}$ \\
\hline Martin et al. $2008^{11}$ & $\begin{array}{l}\text { Prospective } \\
\text { screening study }\end{array}$ & 21159 & $\begin{array}{l}\text { LUTS are positively associated with } \\
\text { localized prostate cancer. No data on } \\
\text { biopsy sampling }\end{array}$ \\
\hline
\end{tabular}

PCa: prostate cancer; LUTS: lower urinary tract symptoms; AUASS: American Urological Association Symptom Score; IPSS: International Prostate Symptom Score. 


\section{COPYRIGHT ${ }^{\odot} 2017$ EDIZIONI MINERVA MEDICA}

CICIONE

URINARY SYMPTOMS AND PROSTATE CANCER

Men who had previously undergone PBx or invasive treatment for benign prostatic hyperplasia, or with dwelling urethral catheters, or with a serum PSA level above 20 $\mathrm{ng} / \mathrm{mL}$, or with high-grade prostatic intraepithelial neoplasia (HGPIN) or atypical small acinar proliferation (ASAP) of prostate were excluded from the present case-control study.

Finally, all participating sites provided the necessary institutional data-sharing agreements that included both local ethical committee approval and patient written consent to clinical data access for research purpose.

\section{Statistical analysis}

Clinical characteristics were considered continuous variables and reported as means; those with normal distribution, according to the Kolmogorov-Smirnov Test, were compared by Student's $t$-test for paired or unpaired data, whereas those with a non-parametric distribution were compared by the MannWhitney U-Test for independent groups. Frequencies were compared by the $\chi^{2}$ Test. The combined predictive effect of the covariates was tested by logistic regression analysis, performing a backward selection procedure with a removal criterion of $\mathrm{P}>0.10$ based on the likelihood ratio test. Model calibration was measured by the Hosmer-Lemeshow goodness of fit test, with $\mathrm{P}<0.05$ considered statistically significant.

Finally, receiver operator characteristic (ROC) curves analysis was used to determine whether the addition of the IPSS increased the predictive accuracy of multivariate logistic regression models based on standard clinical parameters (age, PSA, DRE, and prostate volume). IPSS as symptom severity index was categorized into mild (range score 0-7), moderate (range score 8-19) and severe (range score 20-35). ${ }^{13}$

All records were collected in a common dedicated datasheet and analyzed using SPSS v. 19 software (SPSS Inc, IBM Corp, Somers, NY, USA). Statistical significance was set at $\mathrm{P}<0.05$.

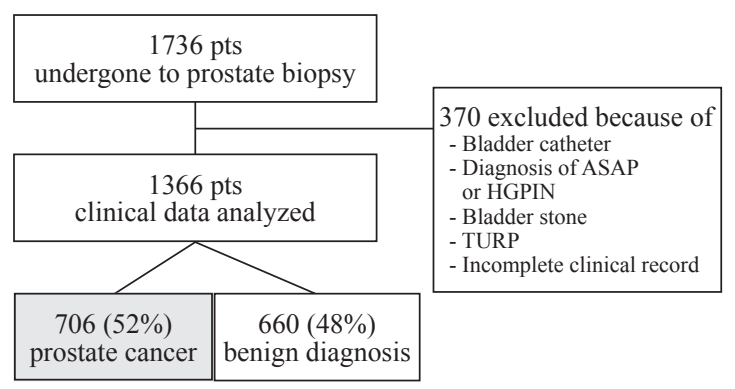

Figure 1.-Algorithm showing patients selection and exclusion criteria for present study.

\section{Results}

Between January 2012 and June 2015, a total of 1736 patients underwent TRUS-guided PBx at the four institutions; 1366 patients met the inclusion criteria and were enrolled in the present study (Figure 1). Their descriptive characteristics are summarized in Table II. PCa was found in 706 (52\%) patients, while the remaining 660 (48\%) had no evidence of malignancy.

Univariate analysis showed a statistically significant difference in all tested variables (age, PSA, DRE, prostate volume and IPSS) between patients with and without $\mathrm{PCa}$ (Table II). Multivariate logistic regression analysis showed that age, PSA, prostate volume and IPSS were the most significant predictors of PBx outcome, with the Hosmer-Lemeshow statistics showing adequate model calibration (Tables III, IV). Interestingly, the PCa detection rate was found to be inversely correlated to LUTS severity.

TABLE II.-Patients features according to prostate biopsy diagnosis.

\begin{tabular}{lccc}
\hline Mean \pm SD or cases (\%) & $\begin{array}{c}\text { Cancer } \\
\text { N. 706 }\end{array}$ & $\begin{array}{c}\text { Benign } \\
\text { N. 660 }\end{array}$ & \multirow{2}{*}{ P } \\
\hline AGE, years & $69.1 \pm 7.5$ & $65.6 \pm 7.4$ & 0.001 \\
Prostate volume, cc & $46.5 \pm 23.1$ & $64.2 \pm 29.2$ & 0.001 \\
PSA, ng/mL & $7.7 \pm 3.8$ & $6.7 \pm 3.2$ & 0.001 \\
IPSS total & $10.6 \pm 7.4$ & $12.7 \pm 8.1$ & 0.001 \\
Positive DRE findings & $142(19.5)$ & $40(5.7)$ & $0.001 \S$ \\
Luts severity & & & \\
$\quad$ Mild (IPSS 1-7), 509 & $292(57.4)$ & $217(42.6)$ & $0.001 \S$ \\
Moderate (IPSS 8-19), 607 & $315(51.9)$ & $292(48.1)$ & \\
Severe (IPSS 20-35), 250 & $99(39.6)$ & $151(60.4)$ & \\
\hline
\end{tabular}

Student $t$-test and $\xi^{2}$ Test; IPSS: International Prostate Symptom Score; PVR: post void residual urine volume; DRE: digital rectal examination. 
TABLE III.-Logistic model assessing clinical and pathological variables predictive of prostate cancer on prostate biopsy. IPSS analyzed as ordinal variable.

\begin{tabular}{|c|c|c|c|c|}
\hline & \multirow{2}{*}{$\begin{array}{l}\text { Odds } \\
\text { ratio }\end{array}$} & \multicolumn{2}{|c|}{$\begin{array}{c}95 \% \\
\text { confidence } \\
\text { interval }\end{array}$} & \multirow{2}{*}{$P$} \\
\hline & & $\begin{array}{c}\text { Lower } \\
\text { limit }\end{array}$ & $\begin{array}{l}\text { Upper } \\
\text { limit }\end{array}$ & \\
\hline AGE, years & 1.61 & 1.41 & 1.81 & 0.001 \\
\hline Prostate volume, cc & 0.97 & 0.96 & 0.97 & 0.001 \\
\hline $\mathrm{PSA}, \mathrm{ng} / \mathrm{mL}$ & 1.20 & 1.16 & 1.25 & 0.001 \\
\hline DRE findings & 1.77 & 0.96 & 3.26 & 0.06 \\
\hline IPSS" & 0.74 & 0.61 & 0.91 & 0.004 \\
\hline \multicolumn{5}{|c|}{$\begin{array}{l}\text { Hosmer-Lemeshow Fit Test } 8 \mathrm{P}=0.45 \text {. } \\
\text { DRE: digital rectal examination; IPSS: International Prostate Symp } \\
\text { tom Score. } \\
\text { \#increasing of one unit in IPSS Score up to } 35 \text {. }\end{array}$} \\
\hline
\end{tabular}

Finally, ROC curve analysis (Figure 2) showed that the addition of the IPSS to the multivariate logistic regression model based on standard clinical parameters (age, PSA, DRE and prostate volume) significantly increased the model predictive accuracy (AUC 0.776 vs. 0.652 , respectively; $\mathrm{P}=0.001)$.

\section{Discussion}

The present study confirmed that patients with PCa are older, have higher PSA levels and smaller prostate volume than those without PCa. It also demonstrated an inverse correlation between LUTS, as assessed by the IPSS, and the risk of candidates to $\mathrm{PBx}$ being diagnosed with $\mathrm{PCa}$, therefore adding information to this controversial issue.

In 1994, Catalona et al. ${ }^{4}$ first pointed out that the absence of LUTS was predictive of $\mathrm{PCa}$ in patients scheduled for PBx because of an elevated PSA ( $\geq 4 \mathrm{ng} / \mathrm{mL})$ and/or suspicious DRE findings. This finding was confirmed in a subsequent prospective study whereby an American Urological Association Symptom Score (AUASS) less than 7 was predictive of positive PBx. ${ }^{5}$ However, both studies relied on a sextant prostate sampling.

In a cross-sectional analysis including 65871 patients from the ProtecT study (Prostate testing for cancer and Treatment), Collin et al. ${ }^{6}$ demonstrated, in men with a PSA level of $\geq 3 \mathrm{ng} / \mathrm{mL}$, an inverse correlation between
TABLE IV.-Logistic model assessing clinical and pathological variables predictive of prostate cancer on prostate biopsy. IPSS analyzed as symptom index gravity.

\begin{tabular}{|c|c|c|c|c|}
\hline & \multirow{2}{*}{$\begin{array}{l}\text { Odds } \\
\text { ratio }\end{array}$} & \multicolumn{2}{|c|}{$\begin{array}{c}95 \% \\
\text { confidence } \\
\text { interval }\end{array}$} & \multirow{2}{*}{$\mathrm{P}$} \\
\hline & & $\begin{array}{l}\text { Lower } \\
\text { limit }\end{array}$ & $\begin{array}{l}\text { Upper } \\
\text { limit }\end{array}$ & \\
\hline AGE, years & 1.06 & 1.04 & 1.08 & 0.001 \\
\hline Prostate volume, cc & 0.97 & 0.96 & 0.97 & 0.001 \\
\hline $\mathrm{PSA}, \mathrm{ng} / \mathrm{mL}$ & 1.10 & 1.05 & 1.15 & 0.001 \\
\hline DRE findings & 1.82 & 0.99 & 3.33 & 0.53 \\
\hline \multicolumn{5}{|l|}{ Luts severity $\#$} \\
\hline Moderate (IPSS 8-19) & 0.80 & 0.58 & 0.08 & 0.155 \\
\hline Severe (IPSS 20-35) & 0.56 & 0.37 & 0.84 & 0.006 \\
\hline
\end{tabular}

Hosmer-Lemeshow Fit Test $12.8 \mathrm{P}=0.11$.

DRE: digital rectal examination; IPSS: International Prostate Symptom Score.

\#mild severity category $v s$. moderate and severe.

LUTS and the risk of being diagnosed with PCa. Noteworthy, the multivariate model used to estimate the association between symptoms and cancer diagnosis was adjusted for age, PSA and paternal or fraternal history of $\mathrm{PCa}$, while LUTS were measured by the shortened 11-item version of International Continence Society male questionnaire. ${ }^{14}$ Unfortunately, the authors could not include prostate volume and DRE findings due to the preliminary study design though, as they acknowledged, such parameters would be considered in any study evaluating predictive models for $\mathrm{PCa} .{ }^{5}$

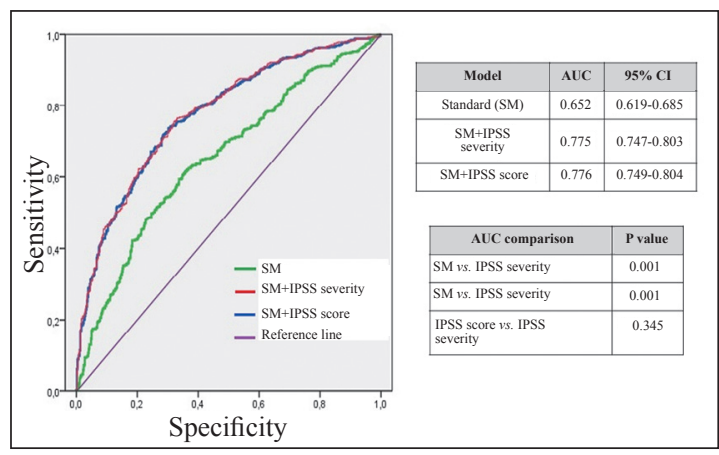

Figure 2.--Receiver operating characteristic (ROC) curves comparing predictive models of prostate cancer based on clinical parameters. The standard model (SM) includes age, prostate specific antigen, prostate volume, digital rectal examination finding. IPSS models include SM plus International Prostatic Symptoms Score (IPSS) analyzed both as categorical (IPSS severity) and ordinal (IPSS Score) variable. 


\section{COPYRIGHT ${ }^{\odot} 2017$ EDIZIONI MINERVA MEDICA}

CICIONE

URINARY SYMPTOMS AND PROSTATE CANCER

The Gothenburg Randomized Screening Trial, ${ }^{7}$ an observational study branch of the European Randomized Study of Screening for prostate Cancer (ERSPC) ${ }^{15}$ performed to assess the impact of PSA screening on mortality, again demonstrated that, in men with a PSA level of $\geq 3 \mathrm{ng} / \mathrm{mL}$, the absence of voiding symptoms was an independent risk factor for PCa detection. This study included age, total PSA, free/total PSA ratio, and prostate volume in the multivariate logistic model demonstrating the inverse correlation (OR 0.78, 95\% CI: 0.63-0.98, $\mathrm{P}=0.032$ ) between voiding symptoms and $\mathrm{PCa}$ diagnosis, but voiding symptoms were investigated by a self-administrated questionnaire contemplating just three answers (1. no symptoms; 2. minor/moderate symptoms; 3 . major/severe symptoms).

Finally, two recent retrospective $\mathrm{PBx}$ cohort analyses 8,9 confirmed the inverse correlation between the IPSS and the risk of being diagnosed with $\mathrm{PCa}$ in the setting of extended ( $\geq 12$-core) PBx. To note a multivariate logistic regression models including age, PSA, DRE, prostate volume and other clinical variables was used. Furthermore, one of those studies ${ }^{8}$ also used ROC curve analysis to determine whether the addition of the IPSS increased the accuracy of the multivariate model devised for the detection of PCa. Oh's et al. ${ }^{9}$ did not show a statistically significative improvement by incorporating IPSS to the PCa predictive model. However, IPSS was considered as a dichotomous variable according to the median value (more or less 11) and a notable difference in cancer detection rate occurs between Oh's study and the present study ( $30 \% v s$. $52 \%$, respectively).

In contrast to the above-mentioned studies, Matsubara et al. ${ }^{10}$ found no correlation between the IPSS and the risk of being diagnosed with $\mathrm{PCa}$, but their study relied on a sextant prostate sampling. Martin et al. ${ }^{11}$ pointed out a direct correlation between LUTS and PCa. However, that study was designed to assess the association of LUTS with a subsequent PCa diagnosis over a follow-up period of almost ten years and showed a positive association between LUTS and localized but not advanced PCa. The authors hypothesized that
LUTS prompt the search for otherwise unsuspected cancers, thus allowing to detect more localized cancers in patients who would have not been investigated in the absence of such symptoms.

Taking all these findings together, it could be assumed that, out of the setting of PSA screening programs, men with LUTS are more likely than the asymptomatic ones to undergo urological investigations and, therefore, to be found with abnormal PSA and/or DRE findings prompting $\mathrm{PBx}$. In men scheduled for PBx because of abnormal PSA and/or DRE findings, however, there is an inverse correlation between presence and severity of LUTS and the risk of being diagnosed with $\mathrm{PCa}$.

The potential relationship between LUTS and increased serum PSA has been pointed out by Laniado et al. already in $2004,{ }^{16}$ as they demonstrated that high PSA levels in patients with LUTS were significantly associated with bladder outlet obstruction (BOO), resulting in $89 \%$ of patients with PSA $>4 \mathrm{ng} / \mathrm{mL}$ having $\mathrm{BOO}$ due to benign prostatic obstruction (BPO). It is attractive to assume that the increased voiding pressure due to $\mathrm{BOO} / \mathrm{BPO}$ could lead to reflux of urine into prostatic ducts with consequent inflammation, PSA increase and consequent potentially unnecessary PBx. Further evidence to such hypothesis has been provided by two recent studies Cormio et $a l .{ }^{17}, 18$ testing the correlation between objective parameters suggestive for BOO, such as peak flow rate and post-void residual urinary volume and the risk of being diagnosed with $\mathrm{PCa}$ at PBx. One study ${ }^{17}$ showed an inverse correlation between the post-void residual urinary volume and the risk of being diagnosed with $\mathrm{PCa}$; the other one ${ }^{18}$ showed an inverse correlation between the presence of $\mathrm{BOO}$, as determined by a peak flow rate $<10 \mathrm{~mL} / \mathrm{s}$, and the risk of being diagnosed with $\mathrm{PCa}$. Interestingly, the addition of post-void residual urinary volume to a multivariate model based on standard clinical factors (age, PSA, DRE and prostate volume) significantly increased the predictive performance of the model in the overall population $(79 \%$ vs. $77 \% ; \mathrm{P}=0.001)$ as well as in the subset of patients with PSA 
levels up to $10 \mathrm{ng} / \mathrm{mL}(74.3 \%$ vs. $71.7 \%$; $\mathrm{P}=0.005)$. Similarly, the present study showed that the addition of the IPSS to the multivariate logistic regression model based on standard clinical parameters (age, PSA, DRE and prostate volume) significantly increased the model predictive accuracy (AUC 0.776 vs. 0.652, respectively; $\mathrm{P}=0.001$ ). That finding was confirmed by analyzing IPSS both as ordinal variable (each score) and categorical (mild LUTS vs. moderate or severe LUTS, Table III) due to the dual interpretation of IPSS.

Unfortunately, the present study did not addressed whether the addition of all three parameters (IPSS, post-void residual urinary volume and bladder outlet obstruction) would have further increased the predictive accuracy of the model based on standard clinical parameters (age, PSA, DRE and prostate volume) as post-void residual urinary volume and bladder outlet obstruction were not collected at all participating centers. This issue deserves further investigations.

\section{Limitations of the study}

Study limitations include a study population consisting of white men only, absence of data about LUTS medication, lack of an external or centralized pathological review, lack of a standard number of cores - though all patients received an extended $\mathrm{PBx}$ including 12 to 18 cores. Similar to other studies, this study was not able to assess the cause of LUTS (i.e. prostatic inflammation, infection, benign prostatic hyperplasia or cancer) due both the absence of a centralized pathological analysis and data on objective findings (i.e. urodynamic study). Then, data about LUTS medication were unavailable, making a more accurate cohort analysis unfeasible (i.e. stratifying patients according to LUTS medication or histological diagnosis)

\section{Conclusions}

The present study analyzed IPSS as both ordinal and categorical variable in order to avoid statistical bias related to the nature of IPSS variable. IPSS needs to be counted as ordinal variable for its confined value or categorical variable when it is considered as symptoms severity index.

Until the role of PSA screening will be fully elucidated, LUTS remain one of the main reason for men seeking urological care. The present multicenter prospective study demonstrated that, in candidates to $\mathrm{PBx}$ because of an elevated PSA and/or a suspicious DRE, there is an inverse correlation between presence and severity of LUTS, as assessed by the IPSS, and the risk of being diagnosed with $\mathrm{PCa}$. Although rating a IPSS threshold to avoid prostate biopsy was unable, the present study supports that the assessment of clinical LUTS is a daily correct clinical practice to perform before scheduling patients to prostate biopsy.

That finding was supported by increasing the predictive accuracy of the model based on standard clinical parameters (age, PSA, DRE and prostate volume) and IPSS, thus providing grounds for incorporating this simple non-invasive clinical parameter into currently available predictive models.

\section{References}

1. Serag H, Banerjee S, Saeb-Parsy K, Irving S, Wright K, Stearn S, et al. Risk profiles of prostate cancers identified from UK primary care using national referral guidelines. Br J Cancer 2012;106:436-9.

2. Bokhorst LP, Zhu X, Bul M, Bangma CH, Schroder FH, Roobol MJ. Positive predictive value of prostate biopsy indicated by prostate-specific-antigen-based prostate cancer screening: trends over time in a European randomized trial*. BJU Int 2012;110:1654-60.

3. Louie KS, Seigneurin A, Cathcart P, Sasieni P. Do prostate cancer risk models improve the predictive accuracy of PSA screening? A meta-analysis. Ann Oncol 2015;26:848-664.

4. Catalona WJ, Richie JP, Ahmann FR, Hudson MA, Scardino PT, Flanigan RC, et al. Comparison of digital rectal examination and serum prostate specific antigen in the early detection of prostate cancer: results of a multicenter clinical trial of 6,630 men. J Urol 1994;151:1283-90.

5. Porter CR, Kim J. Low AUA symptom score independently predicts positive prostate needle biopsy: results from a racially diverse series of 411 patients. Urology 2004;63:90-4.

6. Collin SM, Metcalfe C, Donovan J, Lane JA, Davis M, Neal D, et al. Associations of lower urinary tract symptoms with prostate-specific antigen levels, and screendetected localized and advanced prostate cancer: a casecontrol study nested within the UK population-based ProtecT (Prostate testing for cancer and Treatment) study. BJU Int 2008;102:1400-6. 


\section{COPYRIGHT ${ }^{\odot} 2017$ EDIZIONI MINERVA MEDICA}

CICIONE

URINARY SYMPTOMS AND PROSTATE CANCER

7. Franlund M, Carlsson S, Stranne J, Aus G, Hugosson J. The absence of voiding symptoms in men with a prostatespecific antigen (PSA) concentration of $>/=3.0 \mathrm{ng} / \mathrm{mL}$ is an independent risk factor for prostate cancer: results from the Gothenburg Randomized Screening Trial BJU Int 2012;110:638-43.

8. Ito M, Masuda H, Kawakami S, Fujii Y, Koga F, Saito K, et al. Impact of lower urinary tract symptoms on prostate cancer risk among Japanese men with prostate-specific antigen $<10 \mathrm{ng} / \mathrm{mL}$ and non-suspicious digital rectal examination. Int J Urol 2013;20:1163-8.

9. Oh JJ, Jeong SJ, Jeong CW, Byun SS, Hong SK, Choe $\mathrm{G}$, et al. Is there any association between the severity of lower urinary tract symptoms and the risk of biopsydetectable prostate cancer in patients with PSA level below $20 \mathrm{ng} / \mathrm{ml}$ in multi-core prostate biopsy? Prostate 2013;73:42-7.

10. Matsubara A, Yasumoto H, Teishima J, Seki M, Mita $\mathrm{K}$, Hasegawa $\mathrm{Y}$, et al. Lower urinary tract symptoms and risk of prostate cancer in Japanese men. Int J Urol 2006;13:1098-102.

11. Martin RM, Vatten L, Gunnell D, Romundstad P, Nilsen TI. Lower urinary tract symptoms and risk of prostate cancer: the HUNT 2 Cohort, Norway. Int J Cancer 2008; 123; 1924-8.

12. Cormio L, Pagliarulo V, Lorusso F, Selvaggio O, Perrone A, Sanguedolce F, et al. Combined perianal-intrarectal (PI) lidocaine-prilocaine (LP) cream and lidocaine-ketorolac gel provide better pain relief than combined PI
LP cream and periprostatic nerve block during transrectal prostate biopsy. BJU Int 2012;109:1776-80.

13. Gratzke C, Bachmann A, Descazeaud A, Drake MJ, Madersbacher S, Mamoulakis C, et al. EAU Guidelines on the Assessment of Non-neurogenic Male Lower Urinary Tract Symptoms including Benign Prostatic Obstruction. Eur Urol 2015;67:1099-109.

14. Donovan JL, Peters TJ, Abrams P, Brookes ST, de aa Rosette JJ, Schafer W. Scoring the short form ICSmaleSF questionnaire. International Continence Society. J Urol 2000;164:1948-55.

15. Hugosson J, Carlsson S, Aus G, Bergdahl S, Khatami A, Lodding P, et al. Mortality results from the Goteborg randomised population-based prostate-cancer screening trial. Lancet Oncol 2010;11:725-32.

16. Laniado ME, Ockrim JL, Marronaro A, Tubaro A, Carter SS. Serum prostate-specific antigen to predict the presence of bladder outlet obstruction in men with urinary symptoms. BJU Int 2004;94:1283-6.

17. Cormio L, Lucarelli G, Netti GS, Stallone G, Selvaggio $\mathrm{O}$, Troiano F, et al. Post-void residual urinary volume is an independent predictor of biopsy results in men at risk for prostate cancer. Anticancer Res 2015;35:217582.

18. Cormio L, Lucarelli G, Selvaggio O, Di Fino G, Mancini $\mathrm{V}$, Massenio $\mathrm{P}$, et al. The absence of bladder outlet obstruction is an independent risk factor for prostate cancer in men undergoing prostate biopsy. Medicine (Baltimore) 2016;95:e2551.

Authors' contributions.-Antonio Cicione and Luigi Cormio equally contributed to this study.

Conflicts of interest.-The authors certify that there is no conflict of interest with any financial organization regarding the material discussed in the manuscript.

Article first published online: January 26, 2017. - Manuscript accepted: January 10, 2017. - Manuscript revised: November 4, 2016. Manuscript received: May 23, 2016. 